\title{
CONDIÇÕES DE CONSERVAÇÃO PÓS-COLHEITA DE FRUTTOS DE PIMENTÃO (Capsicum annum L.)
}

\author{
J.C. da S.M. de BARROS; A. de GOES; K. MINANI \\ Departamento de Horticultura, ESALO/USP, C.P.9, CEP: 13418-900 -Piracicaba,SP.
}

\begin{abstract}
RESUMO: Com o objetivo de verificar a conservaçăo de frutos de pimentáo, foi estudada a utilizaçăo de dois tipos de embalagem e um seqüiestrador de etileno, en condigöes ambientais e em geladeira. As avaliaçies foram realizadas a cada cinco dias, obtendo-se as seguintes conclusoes; a melhor temperatura para conservaçäo de pimentoes situa-se entre 7 e $9^{\circ} \mathrm{C}$; 0 armazenamento de pimentzes em bandejas envolvidas com filme de PVC, constitui-se na melhor altermativa para sua conservaçăo, naquela faixa de temperatura. 0 permanganato de potássio, colocado em cápsulas perfuradas no interior das embalagens, não apresenton efeito evidente como absorvente de etileno. Ap6s 30 dias, foram verificadas perdas de frutos por senescencia e/ou pela incidencia de doengas.

Descritores: embalagens, temperatura, conservaça pos-colheita, pimentão.
\end{abstract}

\section{POSTHARVEST PRESERVATION CONDITIONS FOR SWEIT PEPPER FRUITS (Capsicum aurume L.)}

AISTRACT: Two packing types and exponsure to ethylene, in room and refrigerator conditions, were studied for fruits of sweet pepper Agronomico 10G. After 5 day intervals the fruits were weighed. It was concluded that the best temperature range for sweet pepper preservation is 7 to $9^{\circ} \mathrm{C}$; at these temperatures, the best packaging was aluminium trays covered with $0,0165 \mathrm{~mm}$ PVC film. Potassium permanganate in perforated capsules showed no evident effect as ethylene absorbent. After $\mathbf{3 0}$ days fruit losses were very high due to senescence and/or disease incidence.

Keg Wonks: packaging, temperature, postharvest preservation, peppers.

\section{INTRODUÇÃO}

Estima-se que, durante o período entre a collheita e o consumo, as perdas dos produtos hortícolas atingem de 10 a $80 \%$ (FAO). Do local de produção até o consumidor, há uma grande valorização do produto $\mathrm{e}$, consequientemente, qualquer perda após a colheita resulta em acréscimo no custo da comercialização (MEDINA, 1984a).

No Brasil, de acordo com SIGRIST (1983), as perdas pós-colheita de frutos e hortaliças situam-se ao redor de $39 \%$. Na cidade de São Paulo, foi demonstrado que os supermercados apresentam maiores perdas percentuais, porque neles os produtos sofrem manipulação para embalagem. A seguir situam-se as quitandas e, por último, as feiras-livres, onde os produtos são comercializados em menos tempo.

As deteriorações resultantes da fisiologia do produto podem geralmente ser agrupadas como aquelas causadas pelas atividades normais de respiração, transpiração, transformações químicas, amadurecimento e fisiologia anormal das frutas e hortaliças (SIGRIST, 1983).

Em relação d̀s causas físicas, as frutas e hortaliças não podem ser colhidas e manuseadas sem que injúrias a elas ocorram, mas os danos devem ser minimizados.

Assim sendo, métodos de colheita inadequados, impacto, abrasão, atrito, esfoladura, ausência de seleção, classificação, padronização, manuseio inadequado de embalagem, condições precárias de transporte, sobrecarga de frutas transportadas conjuntamente, carência de canais de escoamento do produto, acúmulo de calor ou falta de ventilação nos veículos transportadores, atrasos durante o transporte, condições de armazenamento inapropriado (temperatura, umidade relativa, circulação de ar, sanitização) e equipamentos são as grandes causas físicas de perdas pós-colheita (SIGRIST, 1983).

Já, no tocante às doenças, os patógenos pós-colheita de produtos hortifrutícolas são, na 
maioria das vezes, fungos e bactérias que podem causar sérias perdas, particularmente em hortaliças. Uma altíssima proporção de frutas e hortaliças são destruídas por doenças se elas não forem previamente consumidas ou estabilizadas através do processamento. Além disso, o apodrecimento desses produtos produz considerável etileno, o qual pode causar o amadurecimento prematuro de frutos sadios (SIGRIST, 1983).

De acordo com SIGRIST (1983), as principais causas de perdas pós-colheita para o grupo das hortaliças de frutos imaturos (pepino, abobrinha, berinjela, quiabo, vagem e pimentão), são as seguintes:
1. superamadurecimento na colheita
2. perda de água (murchamento)
3. esfoladuras e outros danos mecânicos
4. distúrbio fisiológico pelo frio
5. deterioração microbiana.

Todos os processos que conduzem à perda de qualidade estão relacionados com a temperatura e umidade relativa do ambiente. A temperatura determina a quantidade de vapor d'água requerida para saturar a atmosfera e afeta tanto a transpiração do produto armazenado como a reação fisiológica predominante e o crescimento dos organismos microbianos. Por esta razão, o controle da temperatura é, provavelmente, o fator mais importante quando se pensa na redução da deterioração do produto armazenado (MEDINA, 1984a e MARTINS el al, 1980).

Segundo MEDINA (1984b), a temperatura ideal recomendada para $O$ armazenamento do pimentão, varia entre 7 a $10^{\circ} \mathrm{C}$. Abaixo de $7^{\circ} \mathrm{C}$, o pimentão está sujeito à injúria pelo frio que é um distúrbio fisiológico. Acima de $10^{\circ} \mathrm{C}$, o processo de maturação, principalmente no que se refere a mudanças de coloração, pode-se desenvolver rapidamente nos frutos e também, nessas temperaturas, os frutos tornam-se mais susceptíveis a podridões. Mesmo nas melhores temperaturas recomendadas, a longevidade dos pimentões não ultrapassa de duas a três semanas.

Quando se pensa no desempenho para estocagem, o ponto relevante é que o pico climatérico retardado significa uma maturação retardada. Esta condição pode ser atingida pela redução da tensão de oxigênio na atmosfera de armazenagem. Quando a concentração de oxigênio é reduziđa para valores abaixo da concentração normal do ar, a taxa de evolução de $\mathrm{CO}_{2}$ é marcadamente afetada, com o pico climatérico retardado e diminuido em sua magnitude. Além disso, o teor de oxigênio reduzido tende a retardar a síntese endógena do etileno (CASTRO, 1984).

Segundo MEDINA (1984a), a perda de água de produtos armazenados não só resulta numa perda de peso, mas também na perda de qualidade, principalmente por causa da textura mais pobre. Alguma perda de água pode ser tolerada, mas aquelas responsáveis pelo murchamento ou enrugamento devem ser evitadas. O murchamento pode ser evitado, reduzindo-se a taxa de transpiração. Há diferentes meios para isto:

a) aumento da UR do ar

b) diminuição da temperatura

c) redução do movimento do ar

d) uso de embalagens protetoras.

A técnica da atmosfera modificada, que consiste no envolvimento das frutas em filmes flexíveis, notadamente o polietileno, vem sendo estudada (CASTRO, 1984). Um dos problemas da aplicação desta técnica, poderia ser a alta umidade dentro do envoltório de polietileno fechado, favorecendo o crescimento de fungos e daí, a necessidade de aplicação, prévia, de fungicidas que possam controlar as principais moléstias do produto na pós-colheita.

Outro problema, pode ser o acúmulo de etileno liberado pelos frutos, dentro do envoltório fechado e o estímulo para o amadurecimento de todo o lote. Este problema pode ser solucionado pelo uso de um produto absorvedor do etileno na embalagem que contém o fruto, prolongando sua durabilidade pela remoção do etileno produzido endogenamente (CASTRO, 1984).

Dentre as muitas técnicas testadas destaca-se a de usar como substrato a vermiculita impregnada de permanganato de potássio $\left(\mathrm{KMnO}_{4}\right)$, como absorvedor de etileno.

DOBRAY \& VERSANYI (1974), avaliando a conservação de frutos e vegetais, verificaram que o uso de filmes plásticos de 0,01 mm de espessura, especialmente quando tratados quimicamente, constituiam a melhor forma para armazenamento dos vegetais estudados, mantendo os produtos frescos, com pequena taxa de deterioração e reduzindo a perda de peso.

Os pimentões podem trazer consigo, do campo, uma carga de microorganismos que, dependendo do manuseio ao qual o produto é submetido, tendem a aumentar e a deteriorá-los. 
Temperaturas e umidades relativas elevadas favorecem sobremaneira o desenvolvimento das doenças de pós-colheita, condições que prevalecem na maioria das áreas de produção da cultura.

Alguns desses patógenos somente encontram condições de se estabelecer e proliferar, após o enfraquecimento dos tecidos vegetais, pela ação do processo de maturação e/ou senescência, ou pela ação da injúria pelo frio.

Para a maioria dos patógenos que ocorrem após a colheita, recomenda-se 0 tratamento com cloro. É suficiente o tratamento do fruto com água clorada, contendo de 100 a 200 ppm de cloro livre, sob a forma de banho de imersão (1 a 3 minutos) (MEDINA, 1984b).

Para patógenos do tipo infecção latente, como é o caso da antracnose, recomenda-se o uso de fungicidas sistêmicos.

No presente trabalho estudou-se o uso de embalagens $\mathrm{e} o$ efeito de permanganato de potássio $\left(\mathrm{KMNO}_{4}\right)$, como absorvente de etileno na conservação de frutos de pimentão, mantidos em condições ambientais e em geladeira.

\section{MATERIAL E MÉTODOS}

O experimento foi conduzido no Laboratório de Fisiologia do Departamento de Horticultura, da Escola Superior de Agricultura "Luiz de Queiroz"/USP, no período de 28 de outubro a 27 de novembro de 1992.

Foram utilizados frutos de pimentão (Capsicum annum L.) 'Agronômico 10G', colhidos em 27 de outubro de 1992 e adquiridos no CEASA de Piracicaba, os quais foram selecionados, submetidos a tratamento antifúngico por imersão durante três minutos em solução de hipoclorito comercial a $1 \%$ e secados ao ar, com auxílio de ventilador, de acordo com MEDINA (1984b) e REINA (1990).

A seguir, os frutos foram uniformizados em tamanho e cor e divididos em lotes de seis, o que constituiu o tamanho de cada parcela, com pesos estatisticamente semelhantes.

Os tratamentos que compuseram o experimento foram em número de dez, objetivando o estudo da utilização de dois tipos de embalagens (sacos plásticos de polietileno, com espessura de $0,03 \mathrm{~mm}$ e bandejas de alumínio revestidas com filme plástico de PVC, de espessura de 0,0165 $\mathrm{mm})$, o permanganato de potássio $\left(\mathrm{KMnO}_{4}\right)$, como seqüestrador de etileno, e o período de conservação em condições ambientais e em geladeira doméstica à temperatura de $8^{\circ} \mathrm{C}+1$.
Dessa maneira, os tratamentos foram assim enumerados:

1. ambiente, sem embalagem, sem $\mathrm{KMnO}_{4}$

2. ambiente, bandeja, com $\mathrm{KMnO}_{4}$

3. ambiente, bandeja, sem $\mathrm{KMnO}_{4}$

4. ambiente, saco plástico, com $\mathrm{KMnO}_{4}$

5. ambiente, saco plástico, sem $\mathrm{KMnO}_{4}$

6. geladeira, bandeja, com $\mathrm{KMnO}_{4}$

7. geladeira, bandeja, sem $\mathrm{KMnO}_{4}$

8. geladeira, saco plástico, com $\mathrm{KMnO}_{4}$

9. geladeira, saco plástico, sem $\mathrm{KMnO}_{4}$

10. geladeira, sem embalagem, sem $\mathrm{KMnO}_{4}$.

Os frutos, devidamente acondicionados em sacos plásticos e em bandejas envolvidas com filme plástico, nas parcelas correspondentes aos tratamentos com $\mathrm{KMnO}_{4}$, foram acompanhados de cápsulas de plástico perfuradas contendo $\mathrm{KMnO}_{4}$ embebido em papel de filtro, na proporção de $7 \mathrm{~g}$ de $\mathrm{KMnO}_{4}$, por cada quilograma de fruto, conforme CASTRO (1984) e REINA (1990).

Sacos plásticos e bandejas com frutos e frutos sem embalagem foram distribuídos em prateleira (condições de ambiente) e em geladeira.

O delineamento estatístico foi inteiramente casualizado ficando, assim, o experimento com 10 tratamentos, 5 repetições e 6 frutos por parcela.

Em condições de ambiente foram anotadas as temperaturas máxima e mínima diárias e as avaliações constaram de peso de frutos e número de frutos em condiçōes normais de consumo, durante todo o período do experimento, sendo as observações realizadas a cada 5 dias.

\section{RESULTADOS E DISCUSSÃO}

Após 30 dias da instalação do experimento, periodo durante 0 qual foram realizadas avaliações a cada 5 dias, foi verificado que ocorreu perda de frutos por maturação excessiva e/ou pela incidência de doenças, causando a inadequação dos frutos para o consumo e ocasionando seu descarte.

Paralelamente, foi observada a perda de peso em todas as parcelas experimentais, gradual e contínua, sendo a maior perda nos tratamentos mantidos em condições ambientais.

Os resultados ao final do período podem ser observados na TABELA 1. 
TABELA 1. Médias de número de frutos de pimentão próprios para consumo, peso e percentual de perda de peso 30 dias após a colheita, sob diferentes condições de armazenamento e conservação. 27/11/92

\begin{tabular}{|c|c|c|c|}
\hline $\begin{array}{l}\text { Trata- } \\
\text { mentos }\end{array}$ & $\begin{array}{l}\mathrm{n}^{\circ} \mathrm{de} \\
\text { frutos }\end{array}$ & $\begin{array}{c}\text { peso } \\
(\mathrm{g})\end{array}$ & $\begin{array}{c}\% \text { de perda } \\
\text { de peso }\end{array}$ \\
\hline 1 & $2,8 \mathrm{bc}$ & $166,9 \mathrm{c}$ & $69,9 \mathrm{abc}$ \\
\hline 2 & 0,0 d & $177,7 \mathrm{c}$ & $88,0 \mathrm{ab}$ \\
\hline 3 & $1,4 \mathrm{~cd}$ & $193,8 \mathrm{bc}$ & $82,0 \mathrm{abc}$ \\
\hline 4 & 0,1 d & $143,6 \mathrm{c}$ & $99,3 a$ \\
\hline 5 & $0,4 \quad d$ & $170,6 \mathrm{c}$ & $96,3 a$ \\
\hline 6 & $5,3 a$ & $344,6 a$ & $12,9 \mathrm{~d}$ \\
\hline 7 & $5,3 a$ & $378,5 a$ & $11,6 \mathrm{~d}$ \\
\hline 8 & $4,5 \mathrm{ab}$ & $418,4 a$ & $18,1 \mathrm{~d}$ \\
\hline 9 & $3,0 a b c$ & $390,6 a$ & $44,2 \mathrm{bcd}$ \\
\hline 10 & $4,3 \mathrm{ab}$ & $325,0 \mathrm{ab}$ & $32,8 \mathrm{~cd}$ \\
\hline
\end{tabular}

Observações: Médias seguidas por letras distintas diferem entre si pelo teste de Tukey, ao nível de $5 \%$ de significância.

Pôde-se verificar que os tratamentos onde ocorreram as menores perdas de peso e de número de frutos foram na geladeira, com bandeja revestida por filme plástico, com ou sem $\mathrm{KMnO}_{4} \mathrm{e}$ na geladeira no saco plástico com $\mathrm{KMnO}_{4}$. As maiores perdas ocorreram nos tratamentos mantidos em condições ambientais, especialmente, de peso e de frutos nos tratamentos com embalagens com ou sem $\mathrm{KMnO}_{4}$.

Os resultados obtidos na geladeira, com temperatura entre 7 e $9^{\circ} \mathrm{C}$, estão de acordo com as indicações de MEDINA (1984a e 1984b) que considera como temperatura de armazenamento para produtos de origem tropical ou subtropical a faixa entre 5 a $13^{\circ} \mathrm{C}$, especificamente para o pimentão a temperatura situando-se entre 7 e $10^{\circ} \mathrm{C}$. Todavia, segundo esse autor, mesmo nas melhores temperaturas recomendadas a longevidade dos pimentões não ultrapassa de duas a três semanas. No presente experimento, pimentões conservados nas mesmas temperaturas, embalados em bandejas com filme plástico, mantiveram-se em ótimas condições de consumo, por um período de 30 dias, com pouco mais de $10 \%$ de perda de peso.

Os resultados obtidos também não estão de acordo com as observações de MARTINS et al. (1980), os quais em estudo relativo ao efeito de temperaturas sobre a qualidade, respiração $e$ amadurecimento de pimentões, verificaram que pimentão armazenado a $15^{\circ} \mathrm{C}$ conservou-se melhor do que aquele armazenado a $20^{\circ} \mathrm{C}$ e mesmo melhor do que aqueles armazenados a $5^{\circ} \mathrm{C}$ e $10^{\circ} \mathrm{C}$, após três semanas de armazenamento. A superioridade do pimentão armazenado a $15^{\circ} \mathrm{C}$, com relação àquele armazenado a $20^{\circ} \mathrm{C}$, deve-se a menor respiração, pois, temperaturas elevadas aceleram os processos fisiológicos de amadurecimento e senescência. As perdas de peso ocorridas nos frutos dos tratamentos em condições ambientais são explicadas pela intensa perda de água a qual, de acordo com BUSSEL \& KENIGSBERGER (1975), pode ocorrer em pimentão, mesmo em condições de temperatura ideal para armazenamento. Todavia, segundo estes autores, a perda de peso observada foi maior em frutos não embalados, sendo reduzida quando se utilizava filmes plásticos como envoltórios.

Estas observações não se confirmaram nos dados obtidos no trabalho ora desenvolvido, visto que as maiores perdas se verificaram nos tratamentos onde os frutos foram embalados, tanto em sacos quanto em bandejas com filmes plásticos.

A utilização do permanganato de potássio como seqüestrador do etileno, nas condições do experimento, não apresentou qualquer efeito significativo na conservação dos pimentões, o que não concorda com o verificado por CASTRO (1984) quando, pesquisando a conservação de abacates em envoltórios de polietileno com uso de $\mathrm{KMnO}_{4}$, concluiu que este foi eficiente na redução da concentração de etileno e no retardamento da maturação das frutas, prolongando seu período comerciável.

REINA (1990) encontrou em tomates, efeito do $\mathrm{KMnO}_{4}$ como absorvente do etileno. Possivelmente, no presente experimento não foi observado o efeito de $\mathrm{KMnO}_{4}$ devido a diferentes metodologias empregadas. Enquanto os autores citados utilizaram o $\mathrm{KMnO}_{4}$ em mistura com vermiculita, na implantação do experimento foi empregado permanganato de potássio acondicionado em cápsulas perfuradas.

Outro fator considerável na perda de frutos foi a incidência de doenças, especialmente Colletotrichum gloeosporioides. Devido às suas caracteristicas fisiológicas, normalmente permanece na forma de infecções latentes nos frutos, tornando impossível sua detecção por ocasião da seleção e padronização. Embora MEDINA (1984b) recomende o uso de fungicidas sistêmicos após a colheita 


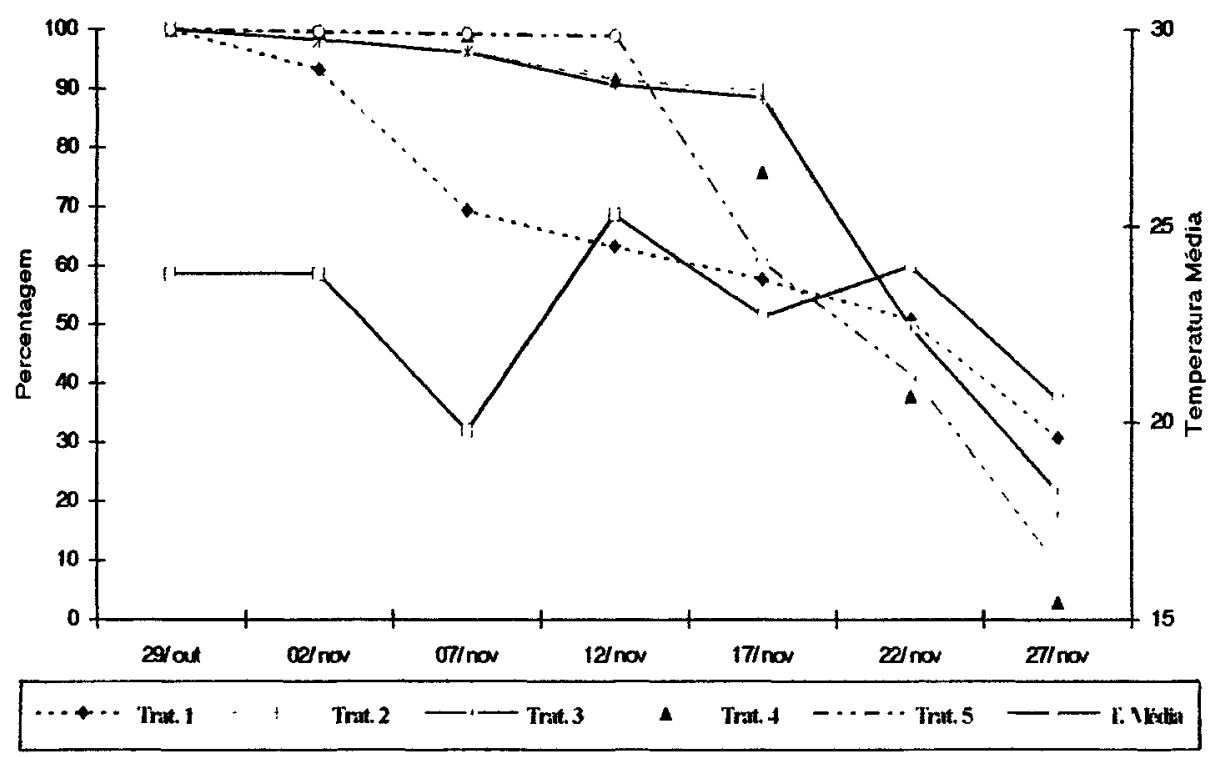

Figura 1. Perdas relativas de peso de frutos de pimentão e variação da temperatura média no período estudado.

do pimentão, no presente trabalho foi utilizado apenas a desinfecção superficial dos frutos, conforme metodologia empregada por REINA (1990).

Além das infecções latentes, as perdas ocasionadas por doenças nos frutos, possivelmente foram incrementadas por condições ambientais favoráveis no interior das embalagens. Tal efeito foi também observado por BUSSEL \& KENIGSBERGER (1975) em pimentões conservados em bandejas envolvidas com filmes plásticos, onde a bactéria Erwinia carotovora foi a causa predominante de perdas de frutos.

TABELA 2. Análise de variância e distribuição das médias de pesos de frutos de pimentão em 27/11/92.

Quadro da análise de variância

\begin{tabular}{lrc}
\hline Causas da variação & G.L. & Valor F \\
\hline Tratamento(peso) & 9 & $13.9 * *$ \\
Resíduo & 40 & \\
\hline TOTAL & 49 & \\
\hline
\end{tabular}

Média geral $=49.8$

Coeficiente de variação $=29.418 \%$

Sci. agric., Piracicaba, 51 (2):363-368, maio/set., 1994
Teste de Tukey para médias de tratamentos

\begin{tabular}{ccc}
\hline$N^{\circ}$ trat. & Médias originais & $1 \%$ \\
\hline 4 & 99.3 & $\mathrm{~A}$ \\
5 & 96.3 & $\mathrm{~A}$ \\
2 & 88.0 & $\mathrm{AB}$ \\
3 & 82.0 & $\mathrm{AB}$ \\
1 & 69.9 & $\mathrm{ABC}$ \\
9 & 44.2 & $\mathrm{BC}$ \\
10 & 32.8 & $\mathrm{BC}$ \\
8 & 18.1 & $\mathrm{C}$ \\
6 & 12.9 & $\mathrm{C}$ \\
7 & 11.6 & $\mathrm{C}$ \\
\hline
\end{tabular}

Médias seguidas por letras distintas diferem entre si ao nível de significância indicado.

D.M.S. $5 \%=31.3$; D.M.S. $1 \%=37.1$

Transformações das observações segundo arco seno da raiz de $X / 100$.

Na TABELA 2, podem ser observados quadros de análises de variância e de classificação estatística de médias e, na Figura 1, gráfico de perda percentual de peso de frutos em relação às variações de temperatura, nos tratamentos mantidos sob condições ambientais. 


\section{CONCLUSÕES}

a) a melhor faixa para conservação de pimentões situa-se entre 7 a $9^{\circ} \mathrm{C}$;

b) o armazenamento de pimentões em bandejas envolvidas com filme de plástico de $0,0165 \mathrm{~mm}$, constituiu-se na melhor alternativa para a sua conservação, naquela faixa de temperatura;

c) o permanganato de potássio, colocado em cápsulas perfuradas no interior das embalagens, não apresentou efeito evidente como absorvente do etileno.

\section{REFERÊNCIAS BIBLIOGRÁFICAS}

BUSSEL, J.; KENIGSBERGER, Z. Packaging green bell peppers in selected permeability films. Journal of Food Science, Champaign, v.40, p.1300-1303, 1975.

CASTRO, J.V. Efeito do permanganato de potássio, do óxido de cálcio e do envoltório de polietileno na conservação de abacate. Boletim do Instituto de Tecnologia de Alimentos, Campinas, v.21, n.4, p.511-526, out/dez. 1984.

DOBRAY, E.; VARSÁNYI, I. Experiments on short-term storage of horticultural products by using plastic films treated with various methods. In: INTERNATIONAL COLLOQUIUM OF PLASTICS IN AGRICULTURE, 5., Budapest, 1972. Proceedings... Budapest: Ministry of Agriculture and Food, 1974, p.650-659
MARTINS, E.S.; CALBO, A.G.; HORINO, Y. Efeito da temperatura sobre a conservação do pimentão cultivar Agronômico 10G. In: CONGRESSO BRASILEIRO DE OLERICULTURA, 20., Brasilia, 1980. Resumos... Brasília, EMBRAPA/ EMBRATER/SOB, 1980. p.164.

MEDINA, P.V.L. Alguns aspectos da fisiologia pós-colheita e a qualidade dos produtos perecíveis. In: CONGRESSO BRASILEIRO DE OLERICULTURA, 24., Jaboticabal, 1984. Palestras. Brasilia: EMBRAPA/DDT, 1984a , p.150-158.

MEDINA, P.V.L. Manejo pós-colheita de pimentões e pimentas. Informe Agropecuário, Belo Horizonte, v. 10, n.113, p.72-76, maio 1984 b.

REINA, L.C.B. Conservação pós-colheita de tomate (Lycopersicon esculentum Mill) da cultivar Gigante Kada submetida a choque a frio e armazenamento com filme de PVC. Lavras, 1990. 114p. Dissertação (Mestrado) - Escola Superior de Agricultura de Lavras.

SIGRIST, J.M.M. Perdas pós-colheita de frutas e hortaliças. In: CEREDA, M.P.; SANCHES, L. Manual de armazenamento e embalagem-produtos agropecuários. Botucatu: Fundação de Estudos e Pesquisas Agrícolas e Florestais, 1983. p.1-12.

Enviado para publicação em 30.08 .93

Aceito para publicação em 05.01 .94 